\title{
Total Synthesis of Lyconesidine B, a Lycopodium Alkaloid with an Oxygenated, Amine-Type Fawcettimine Core
}

\author{
$\operatorname{AUTHOR}(S)$ : \\ Kurose, Tomohiro; Tsukano, Chihiro; Nanjo, \\ Takeshi; Takemoto, Yoshiji
}

\section{CITATION:}

Kurose, Tomohiro ...[et al]. Total Synthesis of Lyconesidine B, a Lycopodium Alkaloid with an Oxygenated, Amine-Type Fawcettimine Core. Organic Letters 2021, 23(3): 676-681

\section{ISSUE DATE:}

2021-02

URL:

http://hdl.handle.net/2433/266607

\section{RIGHT:}

This document is the Accepted Manuscript version of a Published Work that appeared in final form in Organic Letters, copyright $($ American Chemical Society after peer review and technical editing by the publisher. To access the final edited and published work see https://doi.org/10.1021/acs.orglett.0c03816.; The full-text file will be made open to the public on December 16, 2021 in accordance with publisher's 'Terms and Conditions for Self-Archiving'.; This is not the published version. Please cite only the published version.この論文は出版社版でありません。引用の際には出版社版を ご確認ご利用ください。 


\title{
Total Synthesis of Lyconesidine B, a Lycopodium Alkaloid with an Oxygenated, Amine-type Fawcettimine Core
}

\author{
Tomohiro Kurose, ${ }^{\dagger}$ Chihiro Tsukano, ${ }^{\ddagger}, *$ Takeshi Nanjo, ${ }^{\dagger}$ and Yoshiji Takemoto ${ }^{\dagger}, *$ \\ ${ }^{\dagger}$ Graduate School of Pharmaceutical Sciences, Kyoto University, Yoshida, Sakyo-ku, Kyoto 606-8501, Japan \\ * Graduate School of Agriculture, Kyoto University, Kitashirakawa Oiwake-cho, Sakyo-ku, Kyoto 606-8502, Japan
}

\begin{abstract}
This report describes the total synthesis of the complex, oxygenated tetracyclic alkaloid, lyconesidine B. The key synthetic challenge involves diastereoselective generation of a decahydroquinoline ring with a quaternary carbon at the angular position via domino cyclopropanation, ring-opening, and reduction. Another crucial step is the domino ene-yne metathesis involving a quaternary ammonium ion, leading to the construction of a decahydroazaazulen framework. This synthesis requires minimizing catalyst deactivation and approaching the metal carbene with a double bond.
\end{abstract}

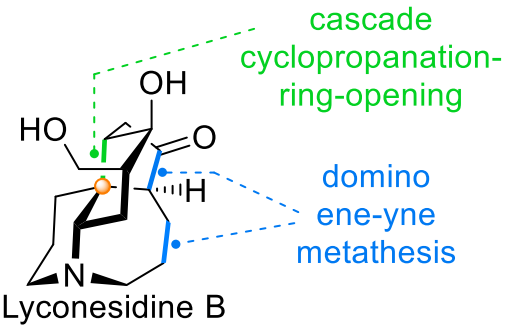

Lyconesidines A and B were first isolated from the club moss, Lycopodium chinense, by Kobayashi and co-workers in 2002 (Figure 1). ${ }^{[1]}$ Their structures, including determination of the absolute stereochemistry, were verified using X-ray crystallography and extensive NMR analysis, including 2D-NMR and a modified Mosher's method. These alkaloids have a complex tetracyclic skeleton containing a cis-hydrindanone (BD ring; Figure 1a) and a hydroazonine with a quaternary carbon center at the angular position. This moiety is part of the basic skeleton of fawcettimine-type alkaloids, which are a major class of $L y$ copodium alkaloids. ${ }^{[2]}$ The oxidation state of $\mathrm{C} 13$ (along the $\mathrm{CD}$ ring juncture, highlighted with a green sphere in Figure 1) in lyconesidines (i.e. amine-type alkaloids) is lower than that in typical aminal- and enamine-type analogs (fawcettimine and fawcettidine structures, respectively; Figure $1 \mathrm{~b}, \mathrm{c}$ ). Therefore, the lyconesidines exhibit distinct D ring conformations, wherein the hydroxymethyl group is located at the axial position. In other words, lyconesidine B is characterized by an oxygen-functionalized amine-type skeleton. Lyconesidines A and B exhibited cytotoxicity against murine lymphoma L1210 cells $\left(\mathrm{IC}_{50}=18.0 \mu \mathrm{g} / \mathrm{mL}\right.$ and $9.5 \mu \mathrm{g} / \mathrm{mL}$, respectively), and inhibited the polymerization of tubulin $\left(\mathrm{IC}_{50}=300 \mu \mathrm{M}\right.$ and $250 \mu \mathrm{M}$, respectively). To our knowledge, there are currently no reports describing a total synthesis of lyconesidines; therefore, we have conducted a synthetic study involving these compounds with the aim of expanding our understanding of their three-dimensional structures and biological activities. Lyconesidine B, which exhibits relatively more potent activity, was used as a target to establish a synthetic route for obtaining analogs bearing oxygen-containing functional groups, ultimately to elucidate structure-activity relationships based on its three-dimensional framework. A synthetic method that allows introduction of functional groups at various positions in a certain skeleton enables synthesis of analogs with several interaction sites designed for a target protein. In this report, we describe the total synthesis of lyconesidine B, which contains a highly-oxygenated amine-type structure, by developing synthetic strategies that can be applied to analog synthesis.

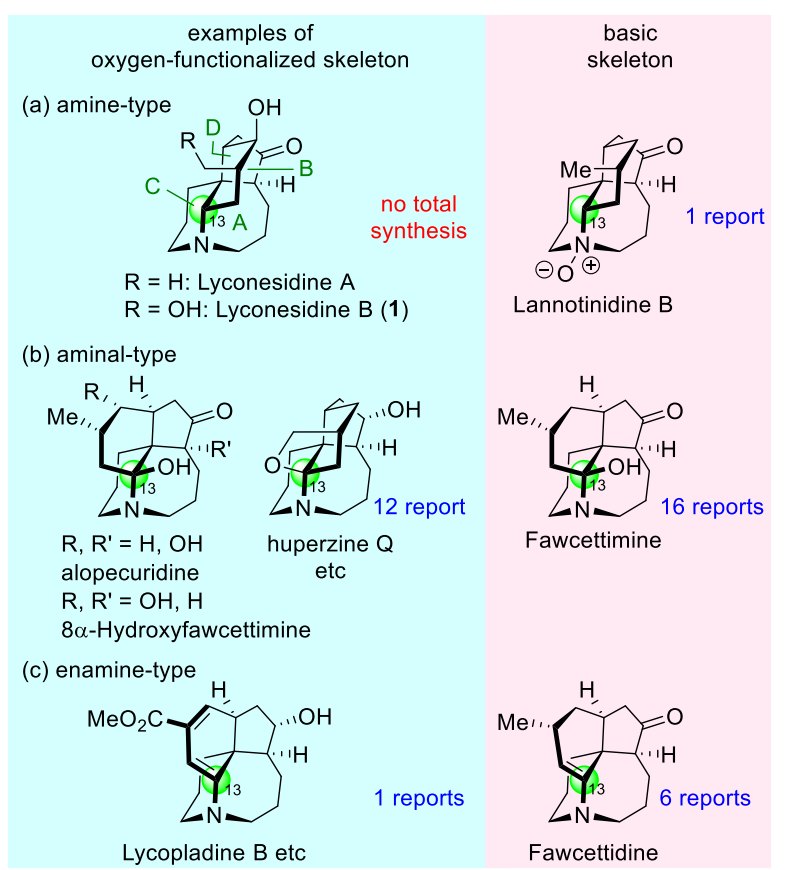

Figure 1. Examples of basic and oxygenated fawcettimine-type alkaloids, noting the number of total synthesis literature reports. (a) Lyconesidines and related amine-type alkaloids, (b) Fawcettimine and related aminal-type alkaloids, and (c) Fawcettidine and related enamine-type alkaloids.

Fawcettimine-type alkaloids have attracted the attention of numerous synthetic organic chemists because of their distinctive structures and biological activities. ${ }^{[3-5]}$ Inubushi and Heathcock reported the pioneering total synthesis of the basic fawcettimine framework, which comprised a cis-hydrindanone (BD ring) fused with hydroazonine. ${ }^{[4 a, b]}$ Although various fawcettimine-type alkaloid syntheses have been reported to date, most of the strategies focus on the aminal- and enamine-type 
structures (Figure 1b,c). ${ }^{[5]}$ To our knowledge, there is only one synthetic study regarding the basic amine-type skeleton, specifically, lannotinidine B. ${ }^{[6]}$ There are no known synthetic reports for the oxygen-functionalized amine-type skeleton, likely because the functional groups on the tetracyclic framework and the relatively lower oxidation state of $\mathrm{C} 13$ limit the strategies and reactions that can be applied to produce these structures. Therefore, a new synthetic approach is required to obtain lyconesidine B.

The synthesis of lyconesidine B poses several challenges, including the construction of a complex, oxygenated, tetracyclic skeleton, as well as the introduction of a quaternary carbon and six contiguous stereocenters, including an axial hydroxymethyl group on the D ring. The lyconesidine B (1) synthetic plan presented herein is based on a domino ene-yne metathesis reaction, ${ }^{[7,8]}$ which generates a decahydroazaazulen structure $(A B$ ring), in combination with a cyclopropanation ring-opening method to obtain the decahydroquinoline (CD ring) (Scheme 1). ${ }^{[9,10]}$ We propose that the tetracyclic skeleton can be modified in a relatively late stage of the synthesis. Specifically, $\mathbf{1}$ is obtained from a tetracyclic compound $\mathbf{2}$ by stereoselectively introducing a hydroxymethyl group. The $\mathrm{AB}$ ring framework is constructed from dieneyne $\mathbf{3}$, which is derived from compound $\mathbf{4}$. To control the reactivity of the double bonds in $\mathbf{3}$ during the metathesis, a crotyl group is introduced on one side. The decahydroquinoline skeleton (CD ring) of $\mathbf{4}$ is constructed via intramolecular cyclopropanation of tetrahydropyridine 6, ring-opening of cyclopropane 5, and reduction of the resulting iminium ion. This one-pot transformation generates the trans ring juncture, including the quaternary carbon center. The cyclization precursor 6 is prepared from a known enol triflate 7. ${ }^{[1]}$ While many approaches involve synthesizing the tetracyclic skeleton from the $\mathrm{BD}$ ring, then forming the azonine ring to construct the $\mathrm{AC}$

Scheme 1. Retrosynthesis of lyconesidine B.
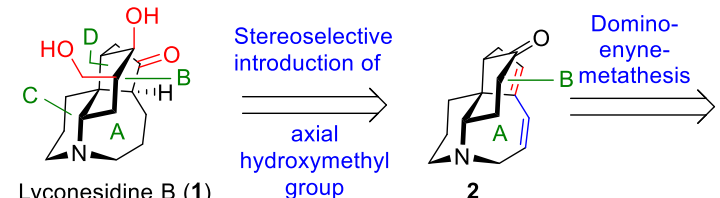

yconesidine B (1)
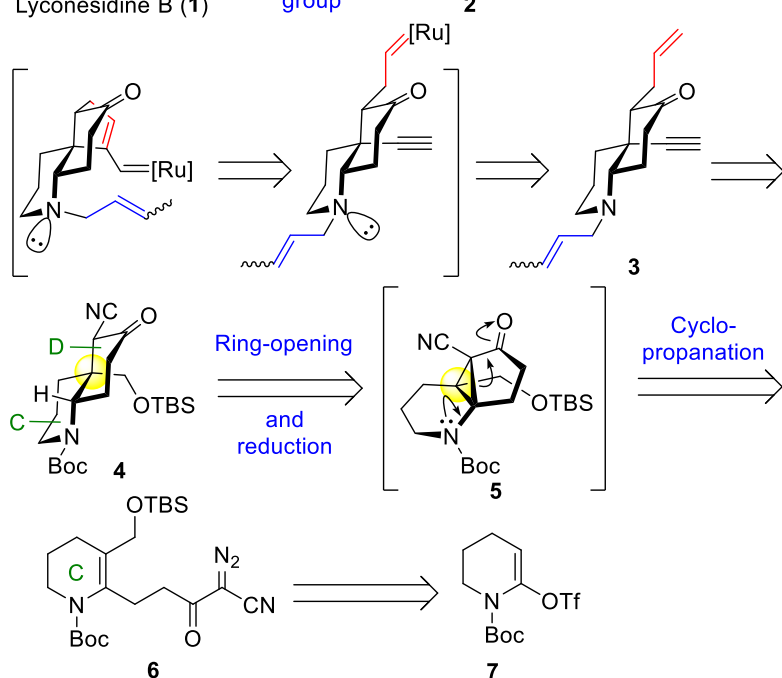

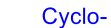
propanation

Scheme 2. Synthesis of the tetracyclic core of lyconesidine B.

ring, the synthetic route described herein is unique because the $\mathrm{CD}$ ring is constructed first, followed by the $\mathrm{AB}$ ring.

The synthesis began with a Suzuki-Miyaura coupling of enol triflate 7 , which was prepared from $\delta$-valerolactam in two steps, ${ }^{[11]}$ with vinyl boronic ester 8 (Scheme 2$) .{ }^{[12]}$ The resulting unsaturated ester 9 was converted to $\mathbf{1 1}$ by $\mathrm{Cu}$-catalyzed 1,4reduction $^{[13]}$ and introduction of an aldehyde moiety using the Vilsmeier reagent. Following the reduction of aldehyde $\mathbf{1 1}$ and silylation of the resulting alcohol, the diazonitrile unit was introduced by treating with deprotonated acetonitrile and performing diazotransfer with 2-azido-1,3-dimethylimidazolinium hexafluorophosphate ${ }^{[14]}$ to afford the cyclization precursor $\mathbf{6}$. This compound can be converted into decahydroquinoline $\mathbf{4}$ using a one-pot process. Applying our previously developed procedure, ${ }^{[9]}$ tetrahydropyridine $\mathbf{6}$ was treated with bis[rho$\operatorname{dium}\left(\alpha, \alpha, \alpha^{\prime}, \alpha^{\prime}\right.$-tetramethyl-1,3-benzenedipropionic acid)] $\left(\mathrm{Rh}_{2}(\mathrm{esp})_{2}\right){ }^{[15]}$ then trifluoroacetic acid (TFA) and $\mathrm{NaBH}(\mathrm{OAc})_{3}$. The reaction proceeded through cyclopropanation, ring-opening of the unstable intermediate 5, and finally, reduction of an iminium ion to generate decahydroquinoline 4 in $45 \%$ yield, along with a small amount of enecarbamate 13 as a byproduct. Because 13 could not be converted to 4 , various reducing agents and $\mathrm{Rh}$ catalysts were investigated to improve the yield and suppress the formation of byproduct 13. It was determined that the combination of $\mathrm{Rh}_{2}(\mathrm{NHCO} t \mathrm{Bu})_{4}{ }^{[16]}$ bearing an amide ligand, and $\mathrm{NaBH}\left(\mathrm{O}_{2} \mathrm{CCF}_{3}\right)_{3}$ (1 equiv.), prepared from $\mathrm{NaBH}_{4}$ and TFA (1:3), ${ }^{[17]}$ provided better results. The reaction under these optimized conditions proceeded smoothly to afford 4 in $72 \%$ yield as the single product. These conditions were reliable and could be applied for decagram-scale synthesis of 4 .

The obtained decahydroquinoline skeleton $\mathbf{4}$ was then converted to the domino ene-yne cyclization precursor 3. Following $O$-allylation, the tert-butyldimethylsilyl (TBS) group was removed to afford the alcohol 14. Oxidation of that alcohol with tetra- $n$-propylammonium perruthenate (TPAP) ${ }^{[18]}$ and introduction of an alkyne moiety using the Ohira-Bestmann reagent generated compound 15. It was essential to introduce the alkyne unit at this stage to avoid steric congestion. After a Claisen rearrangement, the nitrile and tert-butoxycarbonyl (Boc) groups were removed under Birch and acidic conditions, respectively. The resulting amine $\mathbf{1 7}$ was treated with crotyl bromide and a base $\left(\mathrm{K}_{2} \mathrm{CO}_{3}\right)$ to afford the cyclization precursor $\mathbf{3}$, which was used for initial attempts of domino ene-yne metathesis.

First, 3 was treated with $5 \mathrm{~mol} \%$ Grubbs $2^{\text {nd }}$ generation catalyst, but the desired cyclized product 2 was only obtained in $5 \%$ yield. When $50 \mathrm{~mol} \%$ of Grubbs $2^{\text {nd }}$ catalyst was used, 2 was produced in up to $50 \%$ yield, depending on the amount of the catalyst. These results suggested that the catalyst was deactivated by the bridge-head tertiary amine of the product (Scheme 3, path a). Therefore, the addition of Lewis and Brønsted acids, including $\mathrm{Ti}(\mathrm{O} i \mathrm{Pr}){ }_{4}{ }^{[19]}$ and $\mathrm{HCl},{ }^{[8 \mathrm{~h}]}$ was examined as a method to prevent the deactivation of the Grubbs catalyst. However, these conditions did not improve yields, because the crotyl group avoided inversion and remained at the equatorial position. Therefore, to achieve the domino ene-yne metathesis, it is necessary to minimize the tertiary amine's deactivation of the Grubbs catalyst while positioning the crotyl group in the axial conformation for the second cyclization. 

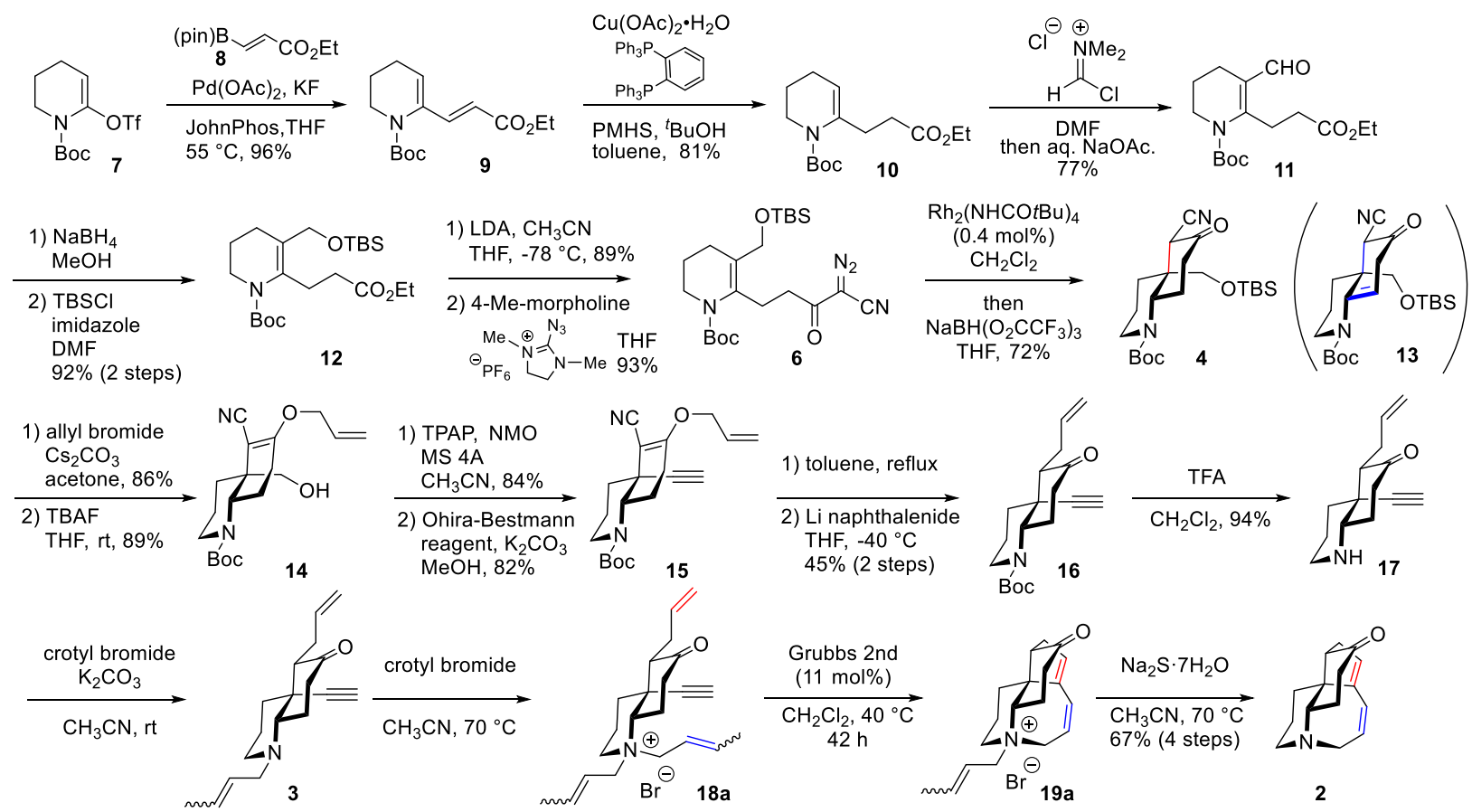

JohnPhos $=2$-(di-tert-butylphosphino)biphenyl, PMHS $=$ polymethylhydrosiloxane, LDA $=$ lithium diisopropylamide, TBAF $=$ tetra- $n$-butylammonium fluoride, $\mathrm{NMO}=N$-methylmorpholine $N$-oxide, $\mathrm{MS} 4 \mathrm{~A}=$ molecular sieves $4 \AA$.

Scheme 3. Constructing of the tetracyclic skeleton via domino ene-yne metathesis.

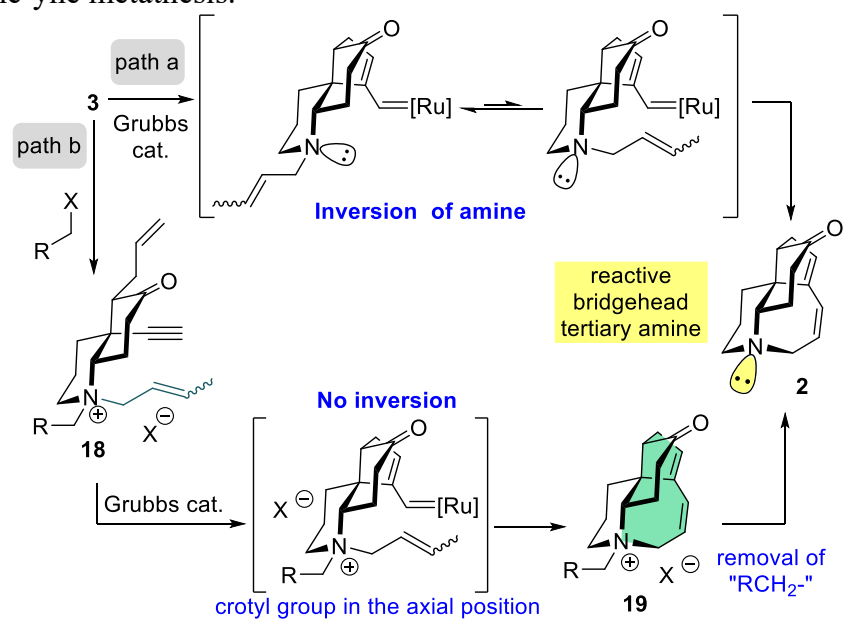

Thus, we expected that the quaternary ammonium salt $\mathbf{1 8}$ would meet these requirements, although the additional substituent must be removed after the cyclization (path $b$ ). The second crotyl group would be best because there is no need to distinguish between the two substituents on the nitrogen atom. It was regioselectively introduced to compound $\mathbf{3}$ at elevated temperature, without using a base $\left(\mathrm{K}_{2} \mathrm{CO}_{3}\right)$ to generate a thermodynamically-stable linear-crotyl product 18a (Scheme 2). The obtained quaternary ammonium salt 18a was treated with 11 mol\% Grubbs $2^{\text {nd }}$ catalyst, and the desired domino cyclization proceeded smoothly to give compound 19a in good yield. The crotyl group could be readily removed by treating with $\mathrm{Na}_{2} \mathrm{~S}$ to obtain the tetracyclic compound 2 . The overall yield was $67 \%$ through crotylation, domino ene-yne metathesis, and de-crotylation. Although it takes 19 steps to access the key tetracyclic skeleton $\mathbf{2}$, from the known triflate 7, this synthetic route generates enough material (over $500 \mathrm{mg}$ ) to synthesize the natural product.

After construction of the tetracyclic compound 2, the total synthesis of lyconesidine B requires regio- and stereoselective introduction of a hydroxymethyl group and an oxygen functionality. Epoxidation of $\mathbf{2}$ with $\mathrm{H}_{2} \mathrm{O}_{2}$ and trichloroacetonitrile ${ }^{[20]}$ afforded $\mathbf{2 0}$ as a single diastereomer, along with oxidation of the bridge-head amine to an $\mathrm{N}$-oxide (Scheme 4). After reductive ring-opening of the epoxide, the resulting allyl alcohol $\mathbf{2 1}$ was converted to 22 through silylation and diastereoselective hydrogenation. The newly generated stereochemistry of $\mathbf{2 2}$ was confirmed by X-ray crystallographic analysis of its salt $(\mathbf{2 2} \cdot \mathbf{H C l})$, as shown in Scheme 4. Diastereoselective introduction of the axial hydroxymethyl group was achieved by Mukaiyama aldol reaction of a silyl enol ether, prepared from ketone 22, with formaldehyde in the presence of $\mathrm{Sc}(\mathrm{OTf})_{3} \cdot{ }^{[21]}$ The $\beta$-hydroxyketone $\mathbf{2 3}$ was produced as a single diastereomer by shielding one side of the silyl enol ether with a bulky siloxane group. After a protecting group manipulation, ketone $\mathbf{2 5}$ was reduced diastereoselectively using the hydroxy group on C5 as the directing group. Selective oxidation of the resulting diol $\mathbf{2 6}$ with 2-azaadamantane- $N$-oxyl (AZADO) ${ }^{[22]}$ was followed by the removal of the triethylsilyl (TES) group to give lyconesidine B (1). The spectral data (high-resolution mass spectrometry (HRMS) and ${ }^{1} \mathrm{H}$ and ${ }^{13} \mathrm{C}$ NMR) obtained for the synthetic lyconesidine $\mathrm{B}$ matched well with those of the natural product. Thus, we achieved the total synthesis of lyconesidine B. ${ }^{[1]}$

Scheme 4. Total synthesis of lyconesidine B. 


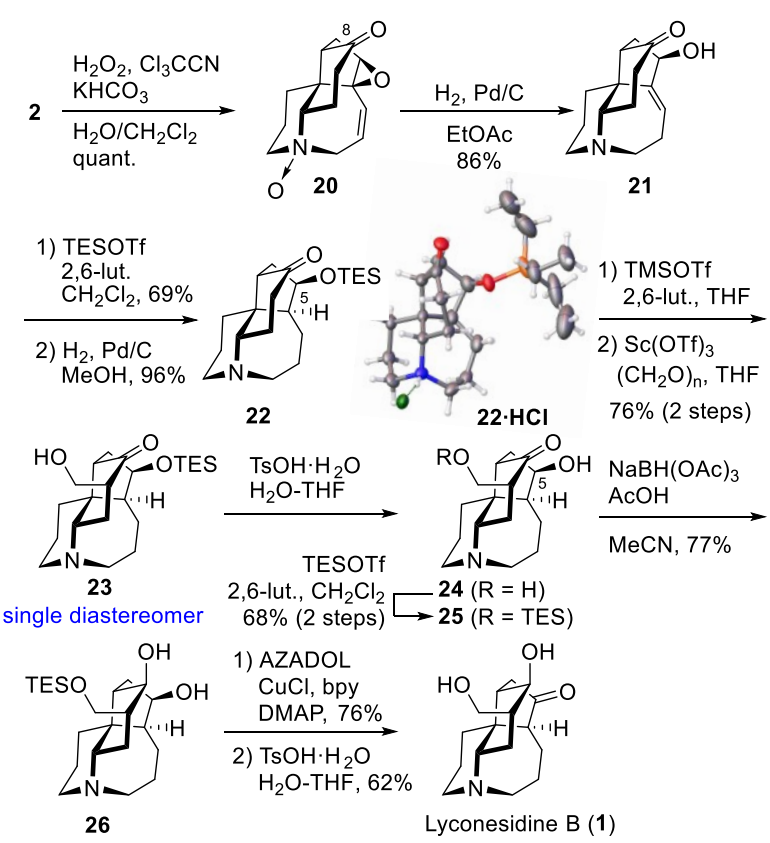

TMS = trimethylsilyl, DMAP = 4-dimethylaminopyridine.

In summary, we have accomplished the total synthesis of lyconesidine $\mathrm{B}$ by applying an original synthetic strategy employing domino reactions to generate a framework comprising decahydroquinoline ( $\mathrm{CD}$ ring) and decahydroazaazulen ( $\mathrm{AB}$ ring). The CD ring, which contains a quaternary carbon center at the angular position, was constructed via cyclopropanation of a tetrasubstituted enecarbamate, followed by ring-opening and diastereoselective reduction. The $\mathrm{AB}$ ring was obtained through a domino ene-yne metathesis, in which a quaternary ammonium ion played an important role in minimizing the deactivation of the Grubbs catalyst and positioning the crotyl group in the axial conformation to allow the second cyclization. The developed synthetic route enabled easy access to the oxygenated aminetype tetracyclic skeleton, which cannot be readily obtained using other established strategies. Follow-up studies are currently underway to investigate the biological activity of these synthetic analogs.

\section{ASSOCIATED CONTENT}

\section{Supporting Information}

The Supporting Information is available free of charge on the ACS Publications website. Experimental procedures, spectral data $\left({ }^{1} \mathrm{H}\right.$ and ${ }^{13} \mathrm{C}$ NMR, IR, and HRMS) (PDF).

\section{AUTHOR INFORMATION}

\section{Corresponding Authors}

* Chihiro Tsukano - orcid.org/0000-0002-9361-0857; E-mail: tsukano.chihiro.2w@kyoto-u.ac.jp

* Yoshiji Takemoto - E-mail: takemoto@pharm.kyoto-u.ac.jp

\section{Notes}

The authors declare no conflicts of interest.

\section{ACKNOWLEDGMENTS}

We gratefully acknowledge Professors Kobayashi J., Morita H., and Hirasawa $\mathrm{Y}$. for providing ${ }^{1} \mathrm{H}$ and ${ }^{13} \mathrm{C}$ NMR spectra of lyconesidine B. We gratefully acknowledge Professors Nemoto T., and Harada $\mathrm{S}$. for providing the Rh catalysts $\left(\mathrm{Rh}_{2}(\mathrm{NHCO} t \mathrm{Bu})_{4}\right)$. This work was supported by a Grant-in-Aid for the JSPS
KAKENHI (JP17H05051 and JP18H04407 C.T.). This research was partially supported by Platform Project for Supporting Drug Discovery and Life Science Research (Basis for Supporting Innovative Drug Discovery and Life Science Research (BINDS)) from AMED under Grant Number JP19am0101092j0003. The authors are grateful for X-ray crystallography from Dr Sato H. of Rigaku.

\section{REFERENCES}

(1) Hirasawa, Y.; Morita, H.; Kobayashi, J. Lyconesidines A-C, new alkaloids from lycopodium chinense. Tetrahedron 2002, 58, 54835488 .

(2) Selected reviews of Lycopodium alkaloids: (a) Hirasawa, Y.; Kobayashi, J.; Morita, H. The Lycopodium Alkaloids. Heterocycles 2009, 77, 679-729. (b) Ma, X.; Gang, D. R.; The Lycopodium alkaloids. Nat. Prod. Rep. 2004, 21, 752-772. (c) Ayer, W. A. The Lycopodium Alkaloids. Nat. Prod. Rep. 1991, 8, 455-463.

(3) Recent reviews on the total synthesis of fawcettimine-type Lycopodium alkaloids: (a) Nakayama, A.; Kitajima, M.; Takayama, H. Syntheses of Fawcettimine-Type Lycopodium Alkaloids Utilizing the Pauson- Khand Reaction. Synlett 2012, 23, 2014-2024. (b) Murphy, R. A.; Sarpong, R. Heathcock-Inspired Strategies for the Synthesis of Fawcettimine-Type Lycopodium Alkaloids. Chem. Eur. J. 2014, 20, 42-56. (4) Selected reports of total synthesis of fawcettimine-type alkaloids containing aminal- or enamine-type skeletons: (a) Harayama, T.; Takatani, M.; Inubushi, Y. Stereoselective Synthesis of Lycopodium Alkaloids, (+)-Fawcettimine and (+)-8-Deoxyserratimine. Tetrahedron Lett. 1979, 44, 4307-4310. (b) Harayama, T.; Takatani, M.; Inubushi, Y. Total Synthesis of the Lycopodium Alkaloids ( \pm )-Fawcettimine and ( \pm )-8-Deoxyserratimine. Chem. Pharm. Bull. 1980, 28, 2394-2402. (c) Heathcock, C. H.; Smith, K. M.; Blumenkopf, T. A. Total Synthesis of $( \pm$ )-Fawcettimine (Burnell's Base A). J. Am. Chem. Soc. 1986, 108, 5022-5024. (d) Heathcock, C. H.; Blumenkopf, T. A.; Smith, K. M. Total Synthesis of ( \pm )-Fawcettimine. J. Org. Chem. 1989, 54, 15481562. (e) Linghu, X.; Kennedy-Smith, J. J.; Toste, F. D. Total Synthesis of (+)-Fawcettimine. Angew. Chem. Int. Ed. 2007, 46, 7671-7673. (f) Kozak, J. A.; Dake, G. R. Total Synthesis of (+)-Fawcettidine. Angew. Chem. Int. Ed. 2008, 47, 4221-4223. (g) Nakayama, A.; Kogure, N.; Kitajima, M.; Takayama, H. First Asymmetric Total Syntheses of Fawcettimine-Type Lycopodium Alkaloids, Lycoposerramine-C and Phlegmariurine-A. Org. Lett. 2009, 11, 5554-5557. (h) Jung, M. E.; Chang, J. J.; Enantiospecific Formal Total Synthesis of (+)-Fawcettimine. Org. Lett. 2010, 12, 2962-2965. (i) Otsuka, Y.; Inagaki, F.; Mukai, C. Total Syntheses of (+)-Fawcettimine and (+)-Lycoposerramine-B. J. Org. Chem. 2010, 75, 3420-3426. (j) Zhang, X.-M.; Tu, Y.-Q.; Zhang, F. M.; Shao, H.; Meng, X. Total Synthesis of $( \pm)$-Alopecuridine and Its Biomimetic Transformation into ( \pm )-Sieboldine A. Angew. Chem. Int. Ed. 2011, 50, 3916-3919. (k) Nakayama, A. Kogure, N. Kitajima, M. Takayama, H. Asymmetric Total Synthesis of a Pentacyclic Lycopodium Alkaloid: Huperzine-Q. Angew. Chem. Int. Ed. 2011, 50, 8025 8028. (1) Yang, Y.-R.; Shen, L.; Huang, J.-Z.; Xu, T.; Wei, K. Application of the Helquist Annulation in Lycopodium Alkaloid Synthesis: Unified Total Syntheses of (-)-8-Deoxyserratinine, (+)-Fawcettimine, and (+)-Lycoflexine. J. Org. Chem. 2011, 76, 3684-3690. (m) Li, H.; Wang, X.; Lei, X. Total Syntheses of Lycopodium Alkaloids (+)-Fawcettimine, (+)-Fawcettidine, and (-)-8-Deoxyserratinine. Angew. Chem. Int. Ed. 2012, 51, 491-495. (n) Pan, G.; Williams, R. M.; Unified Total Syntheses of Fawcettimine Class Alkaloids: Fawcettimine, Fawcettidine, Lycoflexine, and Lycoposerramine B. J. Org. Chem. 2012, 77, 4801-4811. (o) Zaimoku, H.; Nishide, H.; Nishibata, A.; Goto, N.; Taniguchi, T.; Ishibashi, H. Syntheses of $( \pm)$-Serratine, $( \pm)$-Lycoposerramine T, and ( \pm )-Lycopoclavamine B. Org. Lett. 2013, 15, 2140-2143. (p) Zeng, C. Zheng, C.; Zhao, J.; Zhao, G. Divergent Total Syntheses of (-)-Lycopladine D, (+)-Fawcettidine, and (+)-Lycoposerramine Q. Org. Lett. 2013, 15, 5846-5849. (q) Itoh, N.; Iwata, T.; Sugihara, H.; Inagaki, F.; Mukai, C. Total Syntheses of $( \pm)$-Fawcettimine, $( \pm)$-Fawcettidine, $( \pm)$-Lycoflexine, and $( \pm)$-Lycoposerramine-Q. Chem. Eur. J. 2013, 19, 8665-8672. (r) Hou, S.-H.; Tu, Y.-Q.; Liu, L.; Zhang, F.-M.; Wang, S.-H.; Zhang, X.-M. Divergent and Efficient Syntheses of the Lycopodium Alkaloids (-)-Lycojaponicumin C, (-)-8-Deoxyserratinine, (+)-Fawcettimine, and (+)-Fawcettidine. Angew. Chem. Int. Ed. 
2013, 52, 11373-11376. (s) Li, H.; Wang, X.; Hong, B.; Lei, X. Collective Synthesis of Lycopodium Alkaloids and Tautomer Locking Strategy for the Total Synthesis of (-)-Lycojapodine A. J. Org. Chem. 2013, 78, 800-821. (t) Xu, K.; Cheng, B.; Li, Y.; Xu, T.; Yu, C.; Zhang, J.; Ma, Z.; Zhai, H. Stereocontrolled Total Syntheses of $( \pm)$-Fawcettimine, $( \pm)$-Lycoflexine, and $( \pm)$-Lycoflexine N-Oxide. Org. Lett. 2014, 16, 196-199. (u) Zhang, J.; Wu, J.; Hong, B.; Ai, W.; Wang, X.; Li, H.; Lei, X. Diversity-oriented synthesis of Lycopodium alkaloids inspired by the hidden functional group pairing pattern. Nat. Commun. 2014, 5, 4614. (v) Zaimoku, H.; Taniguchi, T. Redox Divergent Synthesis of Fawcettimine-Type Lycopodium Alkaloids. Chem. Eur. J. 2014, 20, 9613-9619. (w) Zheng, C.; Zhao, J.; Zhao, G. Enantioselective divergent total syntheses of fawcettimine-type Lycopodium alkaloids. Tetrahedron 2015, 71, 64-69. (x) Hong, B.; Li, H.; Wu, J.; Zhang, J.; Lei, X. Total Syntheses of (-)-Huperzine Q and (+)-Lycopladines B and C. Angew. Chem. Int. Ed. 2015, 54, 1011-1015. (y) Hong, B.; Hu, D.; Wu, J.; Zhang, J.; Li, H.; Pan, Y.; Lei, X. Divergent Total Syntheses of (-)-Huperzine Q, (+)-Lycopladine B, (+)-Lycopladine C, and (-)-4epi-Lycopladine D. Chem. Asian J. 2017, 12, 1557-1567. (z) Tanimura S.; Yokoshima, S.; Fukuyama, T. Total Synthesis of Huperzine Q. Org. Lett. 2017, 19, 3684-3686. (aa) Kaneko, H.; Takahashi, S.; Kogure, N.; Kitajima, M.; Takayama, H. Asymmetric Total Synthesis of Fawcettimine-Type Lycopodium Alkaloid, Lycopoclavamine-A. J. Org. Chem. 2019, 84, 5645-5654. (ab) Zeng, X.; Jia, Z.; Qui, F. G. A concise asymmetric total synthesis of (+)-fawcettimine. Tetrahedron Lett. 2020, 61,152329

(5) Recent synthetic studies of Lycopodium alkaloids related to fawcettimine-type alkaloids: (a) Liu, K.-M.; Chau, C.-M.; Sha, C.-K. Intermolecular radical addition reactions of a-iodo cycloalkenones and a synthetic study of the formal synthesis of enantiopure fawcettimine. Chem. Commun. 2008, 44, 91-93. (b) Wang, F.-X.; Du, J.-Y.; Wang, H.-B.; Zhang, P.-L.; Zhang, G.-B.; Yu, K.-Y.; Zhang, X.-Z.; An, X.-T.; Cao, Y.-X.; Fan, C.-A. Total Synthesis of Lycopodium Alkaloids Palhinine A and Palhinine D. J. Am. Chem. Soc. 2017, 139, 4282-4285. (c) Chen, C.-M.; Shiao, H.-Y.; Uang, B.-J.; Hsieh, H.-P. Biomimetic Syntheses of $( \pm)$-Isopalhinine A, $( \pm)$-Palhinine A, and $( \pm)$-Palhinine D. Angew. Chem. Int. Ed. 2018, 57, 15572-15576. (d) Hartrampf, F. W. W.; Furukawa, T.; Trauner, D. A Conia-Ene-Type Cyclization under Basic Conditions Enables an Efficient Synthesis of (-)-Lycoposerramine R. Angew. Chem. Int. Ed. 2017, 56, 893-896. (e) Huang, W.-Y.; Nishikawa, T.; Nakazaki, A. Toward a Synthesis of FawcettimineType Lycopodium Alkaloids: Stereocontrolled Synthesis of a Functionalized Azaspirocycle Precursor. J. Org. Chem. 2018, 83, 11108-11117. (f) Seah, K. Y.; Robertson, J. Investigations of an annulation-fragmentation-spirocyclisation approach to fawcettimine-type Lycopodium alkaloids. Tetrahedron 2019, 75, 130661. (g) Shao, H.; Fang, K.; Wang, Y.-P.; Zhang, X.-M.; Ding, T.-M.; Zhang, S.-Y.; Chen, Z.-M. Tu, Y.Q. Total Synthesis of Fawcettimine-Type Alkaloid, Lycojaponicumin A. Org. Lett. 2020, 22, 3775-3779.

(6) Ge, H.; Zhang, L.; Tan, R.; Yao, Z. Protecting Group-Free Total Synthesis of (-)-Lannotinidine B. J. Am. Chem. Soc. 2012, 134, 12323 12325.

(7) Diver, S. T.; Clark, J. R. in Comprehensive Organic Synthesis, Vol. 5, 2nd ed. (Eds.: P. Knochel, G. A. Molander), Elsevier, 2014, pp. $1302-1356$

(8) Selected examples of ene-yne metathesis: (a) Shi, L.; He, Y,; Gong, J.; Yang Z. Concise gram-scale synthesis of Euphorikanin A skeleton through a domino ring-closing metathesis strategy. Chem. Commun. 2020, 56, 531-534. (b) Wang, Y.; Jäger, A.; Gruner, M.; Lübken, T.;

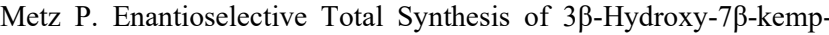
8(9)-en-6-one, a Diterpene Isolated from Higher Termites. Angew. Chem. Int. Ed. 2017, 56, 15861-15865. (c) Betkekar, V. V.; Sayyad, A. A.; Kaliappan, K. P. A Domino Enyne/IMDA Approach to the Core Structure of (-) Vinigrol. Org. Lett. 2014, 16, 5540-5543. (d) Ramharter, J.; Weinstabl, H.; Mulzer, J. Synthesis of the Lycopodium Alkaloid (+)-Lycoflexine, J. Am. Chem. Soc. 2010, 132, 14338-14339. (e) Fukumoto, H.; Takahashi, K.; Ishihara, J.; Hatakeyama, S. Total Synthesis of (+)- $\beta$-Erythroidine. Angew. Chem. Int. Ed. 2006, 45, 2731-2734. (f) Boyer, F. D.; Hanna, H.; Ricard, L. Formal Synthesis of ( \pm )-Guanacastepene A: A Tandem Ring-Closing Metathesis Approach. Org. Lett.
2004, 6, 1817-1820. (g) Honda, T.; Namiki, H.; Kaneda, K.; Mizutani, H. First Diastereoselective Chiral Synthesis of $(-)$-Securinine. Org. Lett. 2004, 6, 87-89. (h) Shimizu, K.; Takemoto, M.; Mori, M. Novel Synthesis of Heterocycles Having a Functionalized Carbon Center via Nickel-Mediated Carboxylation: Total Synthesis of Erythrocarine. Org Lett. 2003, 5, 2323-2325. (i) Huang, J.; Xiong, H.; Hsung, R. P.; Rameshkumar, C.; Mulder, J. A.; Grebe, T. P. The First Successful Base-Promoted Isomerization of Propargyl Amides to Chiral Ynamides. Applications in Ring-Closing Metathesis of Ene-Ynamides and Tandem RCM of Diene-Ynamides. Org. Lett. 2002, 4, 2417-2420. (j) Boyer, F.-D.; Hanna, I.; Ricard. L. Synthesis of Polyoxygenated Bicyclic Systems Containing Medium-Sized Rings from Carbohydrates via Tandem Metathesis of Dienynes. Org. Lett. 2001, 3, 3095-3098. (k) Kim, S.-H.; Bowden, N.; Grubbs, R. H. Catalytic Ring Closing Metathesis of Dienynes: Construction of Fused Bicyclic Rings. J. Am. Chem. Soc. 1994, 116, 10801-10802.

(9) Kurose, T.; Tsukano, C.; Takemoto, Y. Synthesis of Octahydro- and Decahydroquinolines by a One-Pot Cascade Reaction of Tetrasubstituted Enecarbamate. Org. Lett. 2017, 19, 4762-4765.

(10) For recent reviews of ring-opening of aminocyclopropane with an electron-withdrawing group, see: (a) Olga, O.; Bower, J. F. Selective Carbon-Carbon Bond Cleavage of Cyclopropylamine Derivatives. Chem. Rev. 2020, 120, in press, DOI: 10.1021/acs.chemrev.0c00166. (b) Grover, H. K.; Emmett, M. R.; Kerr, M. A. Carbocycles from donor-acceptor cyclopropanes. Org. Biomol. Chem. 2015, 13, 655-671. (c) Schneider, T. F.; Kaschel, J.; Werz, D. B. A New Golden Age for Donor-Acceptor Cyclopropanes. Angew. Chem. Int. Ed. 2014, 53, 5504-5523. (d) de Nanteuil, F.; De Simone, F.; Frei, R.; Benfatti, F.; Serrano, E.; Waser, J. Cyclization and annulation reactions of nitrogensubstituted cyclopropanes and cyclobutanes. Chem. Commun. 2014, 50, 10912-10928.

(11) Tsushima, K.; Hirade, T.; Hasegawa, H.; Murai, A. Conversion of $N$-Acyllactams into $\alpha$-Alkylated Cyclic Enamide via Vinyl Triflate. Chem. Lett. 1995, 9, 801-802.

(12) Jung, H.-Y.; Feng, C.; Kim, H.; Yun, J. Copper-catalyzed boration of activated alkynes. Chiral boranes via a one-pot copper-catalyzed boration and reduction protocol. Tetrahedron 2012, 68, 3444-3449.

(13) Baker, B. A.; Bošković, Ž. V.; Lipshutz, B. H. (BDP)CuH: A "Hot" Stryker's Reagent for Use in Achiral Conjugate Reductions. Org. Lett. 2008, 10, 289-292.

(14) Kitamura, M.; Tashiro, N.; Miyagawa, S.; Okauchi, T. 2-Azido1,3-dimethylimidazolinium Salts: Efficient Diazo-Transfer Reagents for 1,3-Dicarbonyl Compounds. Synthesis 2011, 7, 1037-1044.

(15) Espino, C. G.; Fiori, K. W.; Kim, M.; Du Bois, J. Expanding the Scope of C-H Amination through Catalyst Design. J. Am. Chem. Soc. 2004, 126, 15378-15379.

(16) Harada, S.; Kono, M.; Nozaki, T.; Menjo, Y.; Nemoto, T.; Hamada, Y. General Approach to Nitrogen-Bridged Bicyclic Frameworks by Rh-Catalyzed Formal Carbenoid Insertion into an Amide $\mathrm{C}-\mathrm{N}$ Bond. J. Org. Chem. 2015, 80, 10317-10333.

(17) Logan, M. M.; Toma, T.; Thomas-Tran, R.; Du Bois, J. Asymmetric synthesis of batrachotoxin: Enantiomeric toxins show functional divergence against $\mathrm{Na}_{\mathrm{v}}$. Science 2016, 354, 865-869.

(18) Ley, S. V.; Norman, J.; Griffith, W. P.; Marsden, S. P. Tereapropylammonium Perruthenate, $\mathrm{Pr}_{4} \mathrm{~N}^{+} \mathrm{RuO}_{4}^{-}$, TPAP: A Catalytic Oxidation for Organic Synthesis. Synthesis 1994, 1994, 639-666.

(19) Yang, Q.; Xiao, W.-J.; Yu, Z. Lewis Acid Assisted Ring-Closing Metathesis of Chiral Diallylamines: An Efficient Approach to Enantiopure Pyrrolidine Derivatives. Org. Lett. 2005, 7, 871-874.

(20) Holleben, M. L. A.; Livotto, P. R.; Schuch, X. M. Experimental and Theoretical Study on the Reactivity of the R-CN/ $\mathrm{H}_{2} \mathrm{O}_{2}$ System in the Epoxidation of Unfunctionalized Olefins. J. Braz. Chem. Soc. 2001, $12,42-46$.

(21) Kobayashi, S.; Hachiya, I.; Ishitani, H.; Araki, M. Scandium Trifluoromethanesulfonate $\left(\mathrm{Sc}(\mathrm{OTf})_{3}\right)$ as a Novel Reusable Lewis Acid Catalyst in Aldol and Michael Reactions. Synlett 1993, 1993, 472-474. (22) Sasano, Y.; Nagasawa, S.; Yamazaki, M.; Shibuya, M.; Park, J.; Iwabuchi, Y. Highly Chemoselective Aerobic Oxidation of Amino Alcohols into Amino Carbonyl Compounds. Angew. Chem. Int. Ed. 2014, $53,3236-3240$. 
